\title{
INDISSOCIABILIDADE ENTRE TURISMO, TRANSPORTE E LOGÍSTICA.
}

\author{
João Carlos Souza \\ Universidade Federal de Santa Catarina \\ joao.carlos@ufsc.br
}

\begin{abstract}
Resumo
O transporte está cada vez mais presente na sociedade contemporânea. O desenvolvimento econômico e social e de uma região depende, dentre outros fatores, de sistemas de transportes avançados que propiciem a integração e a expansão e melhoria dos sistemas de produção, favorecendo assim seu crescimento. A intrínseca relação entre os sistemas de transportes e a atividade turística é inegável. Como a atividade turística se constitui em movimentar e manter pessoas fora de seu local de residência e sua rotina profissional habitual, é necessário que seja planejado e construído todo um aparato para hospedar, abastecer e transportar estas pessoas, garantindo um bom nível de serviço e segurança. $O$ turismo, os sistemas de transportes e a logística possuem uma estreita relação de dependência. O planejamento dos transportes para o atendimento do setor turístico trata, pois, das facilidades na movimentação de pessoas e bens, incluindo as operações de deslocamentos, terminais e sistemas de controle de tráfego. Ele fundamenta-se na análise do desenvolvimento histórico da demanda existente, nas metas e objetivos da demanda futura em função do desenvolvimento da atração turística e na provisão de um sistema de transporte que atenda satisfatoriamente a esta demanda. O objetivo deste trabalho foi analisar as características dos sistemas de transportes utilizados para o turismo e avaliar as implicações para com os sistemas logísticos.
\end{abstract}

Palavras chave: Transporte, Logística, Turismo.

\begin{abstract}
Transport, logistics and tourism industry are increasingly present in contemporary society. The economic and social development of a region depends on advanced transport systems that facilitate the integration and the expansion and improvement of production systems, favoring its growth. The intrinsic relationship between logistic, transport systems and tourist activity is undeniable. As tourism is constituted by moving and keeping people out of their usual locations and professional routines, it must be planned and constructed to host a whole apparatus, fueling and transporting these people, ensuring a good level of service and safety. To ensure support for tourism industry, rigorous planning of the transport sector and logistics activities, with reliable predictions of displacement and the operations of the terminals and control systems becomes necessary. This paper analyzes the characteristics of the logistics and transportation systems used for tourism and assesses the implications for logistics systems.
\end{abstract}

Keywords: $\quad$ Transport, Logistic, Tourism. 


\section{INTRODUÇÃO}

O transporte pode ser interpretado como a atividade que interliga a origem de uma viagem turística a um determinado destino e vice-versa. Pode também interligar vários destinos turísticos primários e secundários entre si e, além disso, também fazer que os visitantes se desloquem dentro de um mesmo destino primário ou secundário. Historicamente, o desenvolvimento do turismo está muito ligado ao do transporte, uma vez que, por implicar em deslocamentos para fora do lugar de residência habitual, o transporte fornece a ligação essencial entre a moradia e os locais de interesse do viajante.

O turismo, os sistemas de transporte e a logística possuem uma estreita relação de dependência. Com o grande aumento da indústria turística, houve a necessidade de aumentar e instalar a infraestrutura; como os meios de hospedagens, restaurantes, saneamento básico, sistemas de transporte, etc. A infraestrutura de transportes é um componente importante para o turismo, mas sua estreita relação entre os projetos turísticos e a qualidade do meio ambiente faz com que os impactos ambientais negativos destes empreendimentos causem degradação ao meio ambiente. O objetivo deste trabalho é analisar as características dos sistemas de transportes utilizados para o turismo e sua relação com a logística.

\section{CARACTERÍSTICAS DOS TRANSPORTES}

De acordo com Mello (1984), a função de aproximar mercados com o menor custo ou tempo de viagem torna, até certo ponto, complexa a tarefa de definir qual o mais adequado sistema de movimentação, para atender as condições impostas pela demanda econômica. Cada sistema de transporte possui qualidades intrínsecas, que o tornam melhor que os demais em certas situações, porém não foi ainda inventado um meio de transporte que possa ser utilizado sem restrições em qualquer situação. $\mathrm{O}$ autor também afirma que, o fato de ser basicamente uma atividade meio tira dos sistemas de transportes a responsabilidade pela geração de suas demandas, ou seja, não lhes cabe a decisão de onde, quanto ou quando produzir, lhes cabe apenas a responsabilidade de deslocar, de um ponto para outro, pessoas e bens, com o máximo de segurança, no menor tempo e aos menores custos possíveis.

Andrade (1994) salienta que os sistemas de transportes não são planejados para competirem entre si, mas para mutuamente se complementarem. Sua economia de escala advém de operações processadas de forma integrada, aproveitando-se as vantagens comparativas oferecidas por cada modalidade. No processo de planejamento das economias modernas, os transportes têm se caracterizado com vitais e indispensáveis, apesar de suas funções eminentemente intermediárias. Aos sistemas de transportes é atribuída toda a movimentação de bens e pessoas promovida pelo processo econômico.

O profundo relacionamento que existe entre os sistemas de transporte e as regiões por eles servidas dificulta extrapolar de um país para outro alguns conceitos, ou seja, é difícil, se não impossível, universalizar certas características relativas aos transportes, como a repartição modal, por exemplo. A maneira: pela qual o total de pessoas e mercadorias movimentadas numa área, num certo período, se reparte entre as diferentes modalidades disponíveis, variará de país a país, dependendo de seus aspectos físicos e econômicos, tornando, portanto, muito difícil dizer qual a forma mais equilibrada de se dividir o tráfego entre os diversos modos de transportes.

Os planejadores de transporte turístico devem levar em conta o fato de que os usuários 
desses serviços buscarão, sempre que possível àqueles sistemas ou modos que lhes forem mais convenientes e não os que lhes tentem impor. Ao analisar cada alternativa, o usuário, racionalmente, considerará, entre outros, os fatores de confiabilidade, segurança, conforto, custos e tempos. Deve-se sempre partir da premissa de que o consumidor é racional, isto é, ele sempre procurará o serviço que lhe for mais conveniente, e deste modo, além da comparação dos custos, ele considerará outros parâmetros tais como a confiabilidade, a segurança, a freqüência, o tempo de viagem, o conforto, no caso de passageiros, que cada sistema de transporte oferecerá. Esta otimização ao nível de usuário ou nível de empresa nem sempre leva à otimização do ponto de vista macroeconômico.

Observa-se, portanto, que, em relação ao setor turístico, não é fácil precisar uma modalidade que atenda a todo um sistema de movimentação de pessoas e bens . Geralmente se recorre a uma opção envolvendo mais de um modo, porém que funcione de forma integrada e mutuamente complementar. Na prática, essa integração se processa através dos terminais. Estes equipamentos são planejados, projetados, executados e operados com a finalidade de facilitar o transbordo de uma modalidade para outra, tanto para mercadorias como para pessoas. A eficiência e economia proporcionadas por um sistema multimodal integrado dependem das condições físicas, organizacionais e operacionais das modalidades envolvidas, assim como, das facilidades oferecidas pelos pontos de transbordo, os terminais.

O sistema de transporte é formado por quatro elementos principais: a via, representada pelo meio pelo qual o transporte se desenvolve; o veículo, que é o elemento ou dispositivo utilizado para suportar ou conduzir a força transportada, e no qual se aplicam as forças externas que determinam o movimento. A força motriz ou tecnologia propulsora dos veículos, também diz respeito ao seu alcance, velocidade e à lotação a ser transportado; e o terminal, é o lugar no qual se tem acesso os meios de transporte. O mesmo também pode funcionar como forma de transferência de passageiros em trânsito de um modo de transporte para outro ou mesmo entre veículo do mesmo modo (Palhares, 2002).

Dependendo do tipo de via, ou seja, da superfície onde os veículos se movimentarão é que se faz a classificação dos tipos ou modos de sistemas de transportes. De modo geral, os sistemas modais de transportes dividem-se em rodoviário, ferroviário, aquaviário e aéreo. Com o desenvolvimento da tecnologia, outros meios de locomoção vêm sendo descobertos e utilizados, destacando-se os dutos, as correias transportadoras, os veículos que deslizam sobre colchões de ar transportadores em cabos aéreos, os monotrilhos, etc, porém, em função do volume movimentado, ainda não têm a importância dos primeiros.

Os sistemas de transportes pressupõem uma perfeita integração entre suas partes para que seja alcançado o seu fim, que é o de deslocar bens e pessoas de um ponto a outro de uma região, ao menor custo possível. Como se entende por sistema "um conjunto de partes que interagem de modo a atingir um determinado fim, de acordo com um plano ou princípio", para fazê-lo funcionar da maneira desejada é necessário que se façam estudos antes de sua implantação, estes estudos são conhecidos como; planos de transportes.

Não é possível estabelecer-se uma regra geral para a elaboração de um plano de transporte, pois estando os meios de locomoção muito ligados à atividade econômica da região que servem, ficam as soluções dependentes dos padrões locais. Segundo Mello (1984), em transportes não é possível simplesmente copiar os modelos de uma nação para outra, porém, existem algumas etapas que devem ser seguidas na elaboração de qualquer plano de transporte, 
que são:

\subsection{ESTABELECIMENTO DOS OBJETIVOS}

A fixação dos objetivos a serem atingidos pelo plano é o ponto de partida para a sua elaboração, dela em muito dependendo o sucesso das etapas posteriores. Os objetivos serão fixados em função das metas gerais de desenvolvimento da região e dos prazos para os quais são elaborados os planos. Podemos ter objetivos a curto, médio e longo prazo. No primeiro caso, eles deverão ser delineados com maior grau de precisão, enquanto no último, os objetivos em longo prazo poderão ser estabelecidos de forma mais vaga, lembrando que os transportes por si só não se constituem um fim, porém um meio nas atividades exercidas dentro da região em estudo. Os objetivos dos planos de transporte deverão ser sempre orientados para as demais atividades, ou seja, além da movimentação das pessoas, é necessário planejar o seu abastecimento com alimentos e demais produtos para seu conforto.

\subsection{COLETA DE DADOS}

Deverão ser coletados todos os dados referentes às atividades diretamente ligadas aos transportes e aos próprios sistemas, no que diz respeito aos seus meios, vias e terminais. A análise destes dados permitirá uma visão crítica de como estão funcionando as partes integrantes dos sistemas de transporte, detectando-se todos os pontos de estrangulamento. Além da tabulação destes elementos. devem ser tecidos comentários sobre os mesmos e nesta fase é muito importante a participação de especialistas em cada um dos assuntos envolvidos. aproveitando-se o conhecimento factual que os mesmos têm sobre os diversos componentes dos sistemas.

\subsection{PREVISÃO DA DEMANDA}

Na etapa de previsão da demanda deverão ser estabelecidos os volumes de tráfego que utilizarão cada meio e via de transporte. Os planos de transporte são elaborados com vistas a um certo horizonte havendo necessidade da determinação dos futuros volumes de tráfego que utilizarão cada sistema de transporte. Isto é, deve-se prever a demanda global e a repartição modal. Por lidar com o futuro, a previsão da demanda é a fase mais crítica dos planos de transporte, pois trabalha com dados imprecisos e bastante sensíveis por serem dependentes de uma série de fatos econômicos e sociais principalmente as ocorrências conjunturais. Diversas variáveis estarão envolvidas: questões sazonais, comportamento da economia, marketing para divulgação de algum empreendimento turístico existente na região, etc. Não se pode esquecer a superposição dos movimentos dos turistas e dos habitantes locais. A estimativa da demanda futura, mesmo feita com extremo cuidado, deverá apresentar certa margem de erro, principalmente nas regiões em fase de desenvolvimento. A previsão do tráfego futuro pode abranger três etapas:

- Determinação dos volumes de passageiros que a região e da localização das suas origens;

- Tradução dos dados relativos à produção e ao consumo, em termos de volumes de tráfego, definindo-se os fluxos atuais por origem e destino;

- Projeções do tráfego para o futuro, determinando-se a repartição modal, bem como as linhas de movimentação.

A projeção da demanda deve ser feita com o auxílio de modelos matemáticos, sendo mais empregados os modelos de regressão, os quais procuram estabelecer uma relação causal entre a variável dependente $(y)$, o volume de tráfego e as variáveis explicativas da demanda $\left(X_{n},\right)$ : 


$$
y=f\left(X_{1}, X_{2}, \ldots, X_{n},\right)
$$

As variáveis independentes ou explicativas são aquelas que podem explicar a demanda de transportes. Normalmente, as mais utilizadas são a população das diversas origens prováveis dos viajantes, renda média da população, produto interno da região e assim por diante. A escolha da função que será utilizada para projetar o tráfego ficará definida após análise dos coeficientes de correlação, testes estatísticos e análise do comportamento da demanda. É comum em vários estudos de tráfego estipular por antecipação qual o modelo de previsão que será utilizado nos mesmos na regressão linear, por exemplo, porém, isto só deve ser feito após um estudo estatístico completo. É importante neste momento determinar as elasticidades da demanda, principalmente em relação ao preço dos serviços e à renda, pois isto auxiliará na formulação da política a ser adotada para atrair a demanda.

\subsection{ELABORAÇÃO DE PROJETOS ALTERNATIVOS}

Uma vez fixados os objetivos a serem atingidos pelos planos, conhecido o comportamento dos sistemas de transporte e dos demais setores que o afetam ou que por eles são afetados e determinada a demanda futura, pode-se partir para a elaboração de projetos alternativos. Para cada volume de tráfego e cada região haverá um modo de transporte mais apropriado, dentro desta orientação devendo ser elaborados os projetos. Freqüentemente, restrições de natureza financeira limitam o elenco de alternativas e nem sempre é possível implantar o sistema ideal para cada situação; neste caso, deve-se pensar em melhoria por etapas e em garantir os corredores de modo a, progressivamente, irem-se implantando os meios mais apropriados às demandas. Os projetos alternativos devem ser elaborados considerando vários aspectos, como relações entre custos e tarifas, nível de encargos a serem transferidos aos usuários, possibilidade de futura expansão dos sistemas, operações nos terminais, legislação etc.

\subsection{AVALIAÇÃO DOS PROJETOS}

Normalmente o critério utilizado para a avaliação dos projetos de transporte é o da relação Benefício/Custo. Este critério viabilizará ou inviabilizará um projeto apenas em função de seu desempenho econômico, não considerando possíveis benefícios indiretos, uma vez que os benefícios medidos são apenas aqueles passíveis de quantificação em termos monetários, e que atingem os antigos usuários do sistema. Por isto, é bastante inconveniente a utilização indiscriminada da relação $\mathrm{B} / \mathrm{C}$, pois se pode inviabilizar um projeto importante ou viabilizar um que venha a provocar transtornos à sociedade, se olhado de modo mais amplo.

Também bastante empregada é a relação Custo/Eficácia, na qual os custos do sistema são comparados com a sua eficácia, esta medida em termos mais amplos que os benefícios da relação $\mathrm{B} / \mathrm{C}$, pois não se atêm apenas aos valores quantificáveis monetariamente. Esta relação utiliza pesos que são dados à maior ou menor eficácia de um sistema de transporte, sob vários aspectos: tempos de viagem, prejuízos ambientais, facilidade de acesso aos equipamentos turísticos, interferências com o transporte da população local, etc.

De qualquer modo, os critérios de avaliação devem ser alvo de intensa pesquisa, visando à introdução de modificações fundamentais, pois é idéia inteiramente aceita por todos aqueles que elaboram planos de transporte que são bastante incompletos os métodos de avaliação atualmente empregados. Apesar disso, estes critérios devem ser utilizados, pois só através deles é que se poderá ter uma decisão racional sobre a aplicação dos recursos disponíveis ao setor de transporte. 


\subsection{IMPLANTAÇÃO E REAVALIAÇÕES}

Uma vez definidos os projetos prioritários, deve-se passar à fase de implantação, pois "pior que planejar sem implantar é implantar sem planejar"; sem esta fase o plano perderá o seu sentido prático. Quanto às reavaliações, elas são necessárias, porque adaptam os planos às novas situações que dia a dia vão surgindo, evitando que eles fiquem desatualizados com o correr do tempo (Andrade, 1994).

Os sistemas de transporte que servem a uma determinada região compreendem diversas alternativas de movimentação das pessoas e das mercadorias. A capacidade de prestação de serviços deve ser desenvolvida tanto no sentido de atendimento das demandas específicas de cada alternativa como no sentido de manutenção de um equilíbrio entre a capacidade de atendimento individual e a demanda total. O planejamento tem que levar em consideração a evolução da rede de transportes existente, com sua história específica e o papel desempenhado pelas modalidades de transportes, uma por uma, nas diferentes etapas do desenvolvimento econômico da região. É de grande importância, igualmente, a análise das alterações estruturais verificadas no sistema econômico global ou regional e de seus efeitos sobre a demanda de transportes, em geral, e das características próprias de cada modalidade, em particular.

Segundo Andrade (1994), é conveniente esclarecer que, ao longo do tempo, verificam-se alterações na composição da demanda dos diferentes serviços de transportes. Isso se deve, em parte, às alterações nas demandas específicas, que resultam das próprias condições técnicas de melhor atendimento dos acréscimos de fluxos. Mas, em parte, também, essas alterações são devidas às distorções nos custos relativos com que as demandas são atendidas. Torna-se importante, portanto, além do planejamento adequado dos investimentos, uma programação da política tarifária que permita uma operação integrada do sistema de transporte dentro da perspectiva de complementaridade intermodal mencionada anteriormente. Assim, o usuário, ao pagar a tarifa do serviço, deve pagar efetivamente os custos reais de sua prestação. Com isso, tomam-se mais visíveis as situações de complementaridade e ou de competição intermodal.

Dentro do objetivo de coordenação, expresso na situação limite em que a demanda total deva ser atendida a um custo econômico menor para as atividades produtoras, é necessário que a demanda total seja distribuída pelas diferentes modalidades de transporte da maneira mais racional. Assim, examinam-se, nesse nível de planejamento, os fluxos globais de mercadorias e passageiros, traduzidos em tráfego existente e prevê-se a distribuição futura, isto é, que parcela da demanda será atendida por cada modalidade.

$\mathrm{O}$ aperfeiçoamento do planejamento intermodal e as suas possibilidades de sucesso dependem, basicamente, da elaboração de um conjunto de estudos de natureza técnicoeconômica. Esses estudos permitirão complementar as projeções e estimativas provenientes do planejamento global com dados mais concretos relativamente aos fluxos de transportes. É possível afirmar, com efeito, que somente através desses estudos é que os planos de transportes podem ser integrados efetivamente aos planos globais. Os estudos técnico-econômicos deverão permitir, primeiramente, uma identificação geral das necessidades de transportes, através de estudos detalhados das tendências futuras de deslocamentos dos fluxos de um conjunto de mercadorias agrícolas, extrativas e industriais escolhidas.

Cabe ressaltar, finalmente, a importância desses estudos, que se constituem naqueles que relacionam grandes projetos de localização de empreendimentos turísticos com as necessidades de transporte; calculam a capacidade futura de transporte necessária para implementar planos de 
desenvolvimento em regiões selecionadas, que possuem elevado potencial de expansão das atividades econômicas. Do exposto, pode-se concluir que a alocação dos escassos recursos disponíveis, numa economia, só será otimizada pela implantação de projetos definidos em um plano diretor bem elaborado e bem avaliados.

\section{O TRANSPORTE E O TURISMO}

O turismo é um termo amplo, que engloba, além do transporte, muitas outras questões, tais como acomodação, alimentação, e serviços de apoio. Neste sentido, Andrade (1998), faz a seguinte observação: "todos aqueles que viajam precisam receber o conforto proporcional ao custo de seu contrato e à qualidade dos bens e serviços que desejam, e tem o direito de receber antes, durante e depois da viagem". O mesmo autor salienta que apesar da relação entre essas duas atividades, não se pode confundir transporte com turismo. $\mathrm{O}$ turismo começa onde a viagem termina, e, apesar do deslocamento de viajantes conduzir ao turismo, ele não é o turismo propriamente dito, com exceção dos "transportes como turismo" (cruzeiros marítimos, viagens de bicicleta, entre outras).

Contudo, além da complexidade dessa relação, um outro aspecto importante que não deve ser negligenciado quando se trata de transporte turístico, é o fato do mesmo de referir a um serviço, o que muitas vezes dificulta a compreensão e análise, em função de suas características como tal. Tais características, segundo Arantes(2009), se referem à intangibilidade e perecibilidade do serviço e sua inseparabilidade, na qual produção e consumo ocorrem ao mesmo tempo e o serviço não pode ser separado de seus fornecedores.

Palhares (2002), tratando mais especificamente do transporte em relação ao turismo, complementa que este, como serviço, apresenta características singulares, entre elas a capacidade relativamente fixa, não há como aumentar substancialmente a capacidade de oferta de serviços turísticos em um curto espaço de tempo, e os custos fixos altos e marginais baixos, alto preço na compra e manutenção regular do empreendimento e baixo preço na venda unitária do pacote turístico, comparada ao investimento inicial. Além destas, a possibilidade de reservas antecipadas, a demanda variável em função da sazonalidade, o mercado segmentado e a estrutura de preço e custo definida, também são características mencionadas pelo autor

O surgimento de meios de transportes foi determinante no crescimento do turismo, de forma que novos destinos foram acompanhados de novas rotas e meios de transportes para alcançá-los. Santos et all (2006) enfatizam que o turismo no padrão que é atualmente é conhecido no mundo inteiro, só pôde ser alcançado graças ao desenvolvimento tecnológico dos meios de transportes. Por isso, pode-se afirmar que o desenvolvimento dos setores turísticos e de transportes encontra-se intimamente ligado e segue um processo paralelo e de muita influência.

Lamb e Davidson, in Page (2008) colocam que o transporte é um dos três componentes fundamentais do turismo. Os outros dois são o produto turístico, representando a oferta, e o mercado turístico, representando a demanda. Sem dúvida, excluindo-se o transporte, a maioria das formas de turismo não existiria. Em alguns casos, a experiência com os transportes é a própria experiência turística, por exemplo, cruzeiros, viagens de trem em cenários pitorescos e históricos, roteiros de motor-home, automóvel, bicicleta ou à pe, etc. Pode-se afirmar que a infraestrutura de transportes é um pré-requisito básico para o desenvolvimento turístico, embora não se constitua em sua garantia. 
Para entender a complexidade e as relações que coexistem entre o turismo o transporte e a logística, faz-se necessária a construção de uma estrutura que possa sintetizar os diferentes fatores e processos que causam impacto na organização, operação e gestão das atividades associadas à viagem turística. O objetivo de tal estrutura é o de fornecer um meio para entender como os turistas interagem com o transporte, os processos e os fatores envolvidos e os seus efeitos no componente deslocamento, como parte da "experiência turística". Qualquer estrutura existente para análise do transporte turístico necessita considerar o uso do transporte por parte dos turistas, desde a etapa anterior à viagem, na efetivação de reservas, até o término da mesma, e também reconhecer a importância do componente serviço. Ela também deve congregar os diferentes meios de transporte utilizados por turistas, por exemplo, viagem aérea em vôo regular ou fretado, viagem marítima em barcos ou navios de cruzeiro e transporte terrestre, incluindo carro, trem, ônibus, motor-home, motocicleta e bicicleta, Page (2008)

Conforme Arantes (2009), inseridas no uso turístico do transporte, há duas abordagens, que interconectadas ou não, o caracterizam distintamente. Utilizado "para o turismo", onde o transporte se apresenta como um meio para um fim. Nesse caso, o nível de satisfação está relacionado à velocidade e ao custo da viagem, oferecendo baixo valor intrínseco para a experiência da viagem como um todo (Page, 2008). "Como turismo", o meio de transporte é o ponto principal da atividade turística, tal como os cruzeiros, conforme Palhares (2002), oferecendo alto valor intrínseco. Portanto, como percebeu Page (2008), é necessário, se fazer a distinção entre transporte para o turismo e transporte como turismo:

Transporte para o Turismo: onde o transporte é um meio para um fim, sendo muito útil, e o nível de satisfação está relacionado ao custo e à velocidade da viagem, de forma que o meio de transporte não tenha valor direto intrínseco por si só. $\mathrm{O}$ deslocamento é visto tradicionalmente como um custo ao invés de um benefício, quase como custo de oportunidade;

Transporte como turismo: onde o meio de transporte é o contexto para o deslocamento, tal como um cruzeiro, e a base para a experiência turística. Aqui, o princípio do custo do deslocamento, no caso do transporte para o turismo, não se aplica, pois o transporte é o maior benefício, ou pelo menos muitos dos atributos associados ao meio de transporte são benéficos.

O planejamento dos transportes para o atendimento do setor turístico trata, pois, das facilidades na movimentação de pessoas e bens, incluindo as operações de deslocamentos, terminais e sistemas de controle de tráfego. Ele fundamenta-se na análise do desenvolvimento histórico da demanda existente, nas metas e objetivos da demanda futura em função do desenvolvimento da atração turística e na provisão de um sistema de transporte que atenda satisfatoriamente a esta demanda. Compreende, também, o monitoramento e acompanhamento das operações, visando a implantação de possíveis correções decorrentes de alterações no perfil da demanda estimada.

Middleton e Clarke (2001, apud Page, 2008), em um estudo sobre o marketing o transporte no contexto turístico, apontam serviços específicos oferecidos aos turistas, em relação ao transporte. Entre eles tem-se o custo comparado com a concorrência em uma mesma rota, o conforto, a velocidade, o ambiente, a imagem e posicionamento do operador, e conveniência e organização na compra dos bilhetes e o contato com a equipe.

Embora seja amplamente reconhecida a existência de meios de transporte próprios e especializados para o turismo (isto é: ônibus de turismo, vôos fretados, navios de cruzeiros), 
também existem outras formas de transporte que são utilizadas tanto por anfitriões, quanto por turistas em diversas dimensões. Por exemplo, os ônibus urbanos, os sistemas de metrô e os vôos regulares existentes para regiões turísticas são usados simultaneamente por turistas e residentes locais. (Page, 2008).

A distinção dos papéis que o transporte turístico e não turístico exerce traz consigo uma outra problemática, que ainda caracteriza-se pela diferença negligenciada entre o "turista" e o "passageiro", o termo "passageiro" falha ao não distinguir entre as razões para o deslocamento dos turistas, implicando uma relação contratual impessoal, na qual os operadores transportam pessoas entre as regiões, em um sistema de transporte que se preocupa somente com o movimento de passageiros.

Em que pese ao notável avanço tecnológico por que passaram os transportes nos últimos anos, ainda não foi inventado um sistema de movimentação que fosse o mais adequado a deslocar pessoas, bagagens ou outras mercadorias em qualquer situação que envolva a indústria do turismo. Uma série de fatores, que vão desde características físicas ou climáticas regionais até aspectos relativos principalmente à renda dos viajantes, tempo disponível para a viagem, conforto requerido, etc. é que ditarão quais os sistemas de transporte mais indicados. Cada modo de transporte tem seu lugar num sistema complexo de movimentação, dificilmente alguma modalidade pode ser excluída em um plano que vise dotar uma região de sistema adequado para atração e atendimento de turistas.

De acordo com Page (2008), a concorrência entre os diferentes meios de transporte é muito importante, destacando o significado das substituições no transportes para o turismo, onde o preço, a demanda, a oferta e o custo relativo consolidam-se como elementos críticos. Somandose a isto, sabe-se que os meios de transporte turísticos são complementares e as ligações entre os diversos pontos de interesse podem ser consideradas como sendo um "mal necessário" da viagem: alcançar um destino com meios de transporte para o turismo. $\mathrm{O}$ autor argumenta que há também questões mais profundas levantadas pela discussão do transporte turístico, como o fato de que o lazer e a mobilidade turística envolvem desigualdades e podem exercer efeitos substanciais nas comunidades receptoras, uma vez que provocam o deslocamento de um grande número de pessoas para ambientes que não necessariamente comportem suas atividades.

Também surgem debates consequentes da questão crescente sobre os efeitos do transporte no meio ambiente, incluindo a concorrência entre moradores e turistas por espaço nas estradas, cobrança por congestionamentos e competição pelo uso do transporte público. Tais questões tão críticas transcendem a conceituação do turismo e do transporte, devido aos efeitos destes nas localidades. Somando-se à análise existente do transporte no turismo, identificam-se quatro papeis geralmente aceitos e geograficamente expressos para o transporte turístico:

- Ligar o mercado de origem ao destino;

- Proporcionar mobilidade e acesso nos limites internos do destino;

- Proporcionar mobilidade e acesso nos limites do atrativo turístico; e

- Facilitar o deslocamento ao longo de uma rota turística.

Fazer turismo pressupõe a utilização de sistemas de transportes, no entanto, as pessoas que os utilizam procuram otimizar os seus deslocamentos, considerando as qualidades dos transportes sob o seu ponto de vista individual. Segundo Mello (1984), a otimização, assim 
considerada, nem sempre coincidirá com o ótimo global, mas de qualquer modo, as preferências dos usuários deverão ser consideradas na formulação dos planos de implantação ou expansão meios de transportes. A sua análise poderá ainda fornecer indicações sobre o funcionamento dos sistemas e possíveis preferências locacionais em relação à definição de terminais e desenvolvimento da rede viária. Os principais parâmetros de escolha do modo de transporte para fazer turismo, são:

Flexibilidade - Para o turista, a flexibilidade poderá ser relativa à escolha de percursos, frequiência de viagens, controle de tráfego ou vinculação a terminais. Alguns sistemas que são muito flexíveis em relação a algum parâmetro podem não sê-lo em relação a outro. Pode-se citar o caso do transporte aéreo, muito flexível na escolha de rota, porém limitado por esquemas de controle de tráfego e pela necessidade do apoio dos aeroportos, o mesmo podendo-se dizer do transporte marítimo, flexível na escolha elas rotas, porém que perde esta liberdade pela necessidade do apoio de terminais e por problemas técnicos, como profundidade dos canais de acesso e das bacias de evolução. $\mathrm{O}$ transporte rodoviário, pela grande densidade de malha viária e pelas pequenas dimensões dos veículos, é flexível em relação aos caminhos que pode seguir, mas perde a flexibilidade em relação à distância à percorrer e ao tempo de viagem; o ferroviário têm mais flexibilidade em relação ao número de pessoas e ao volume de cargas a ser movimentado, porém os esquemas rígidos do controle de tráfego e a menor densidade da rede o limitam quanto à possibilidade de deslocamentos. Dificilmente, algum sistema gozará de todas as condições de flexibilidade, pois são vários os elementos que de um modo ou outro o limitam.

Velocidade - as modernas economias e, principalmente, os turistas atribuem grande valor ao tempo, logo os meios de transportes mais velozes tenderão a gozar da preferência dos usuários. As reduções nos tempos de viagem poderão permitir um maior tempo de permanência nos pontos a serem visitados.

Custos - é evidente que os custos de transportes serão fator relevante na escolha do modo de transporte ou do itinerário a ser percorrido. Aqui, o usuário deve computar não apenas os custos da viagem, mas também aqueles envolvidos com o tempo de permanência nos terminais.

Confiabilidade - a confiança que o sistema de transporte transmite ao usuário influirá na sua escolha. A confiabilidade está relacionada com cumprimento de horários, não-ocorrência de perdas, avarias ou roubos de suas bagagens durante a movimentação, obediência a escalas e conexões pré-estabelecidas, tradição da prestação de serviços adequados ou qualquer outro parâmetro que possa afetar a confiança do público.

Segurança - diz respeito ao número de acidentes que podem ocorrer. com o sistema, sendo natural a não-preferência por transportes nos quais ocorrem muitos acidentes durante as viagens. Mesmo no turismo de aventura, sempre o maior interesse do viajante é voltar à sua origem sem ter sofrido dano algum à sua integridade física e emocional.

Operação dos terminais - a movimentação de pessoas e de bagagens em terminais de transportes, portos, aeroportos, estações rodoviárias, etc., poderá provocar diversos inconvenientes ou danos às mesmas. Os sistemas de transportes disponibilizados ao turista deverão necessariamente apresentar uma boa operação nos seus terminais, para isto sendo imprescindível que sejam utilizados equipamentos adequados, exista mão-de-obra treinada, sinalização fácil de ser compreendida e um conveniente arranjo físico das instalações. 


\section{ESCOLHA MODAL E O TURISMO}

Pode-se observar que os turistas, aqueles que geram a demanda, são afetados por vários parâmetros em sua escolha modal; deve-se observar que freqüentemente esta poderá recair, mais uma vez, sobre o modo de transporte não mais conveniente dos pontos de vista técnico e econômico, não conduzindo, portanto, a uma otimização da economia como um todo. Caberá ao planejador atender aos desejos dos usuários, e ao mesmo tempo compatibilizá-los com o interesse da coletividade.

A escolha do meio de transporte pelo visitante está relacionada com o motivo da viagem e é afetada por fatores como distância e tempo, conforto e status, utilidade e segurança, comparação de preços dos serviços oferecidos, isolamento e posição geográfica, escala de serviços oferecida e grau de concorrência entre os serviços. A relativa importância dessas grandes influências na escolha do meio irá variar de acordo com o tipo de visitante.

De acordo com Palhares (2002), no Brasil, diferentemente de outros países no mundo, o ônibus é o principal modo de transporte no deslocamento de viagens turísticas. Com isso, não só este modo de transporte é o mais importante nas viagens domésticas, mas também chega a representar mais da metade do total $(55,7 \%)$. Em muitos outros países do mundo, é o automóvel que ocupa essa posição de liderança. A crise que o transporte rodoviário enfrentou no País somado a uma falta de política de transporte que incentivasse esse setor, ao baixo poder aquisitivo da população - o que restringe o uso do modo aéreo ou a aquisição de um automóvel próprio - tornou o ônibus à única opção acessível para a maior parte dos brasileiros.

Existe grande interesse na compreensão e análise da mobilidade turística e o impacto que esta exerce sobre as áreas urbanas, em termos de fluxos de visitas e da demanda de espaço para estacionar veículos, ônibus e outras formas de transporte. Esta questão também já gerou conflitos com os residentes, trabalhadores e os próprios turistas, onde a disputa ocorre em relação às vagas para estacionamento e, em alguns casos, levou a medidas restritivas ou expansivas, que tiveram por intuito atender e harmonizar as necessidades de todos os usuários.

O transporte, para muitos dos destinos urbanos, pode também ser um fator limitador, no qual a escala da cidade, suas atrações e produtos não estão adequadamente interligados por transporte eficiente e não possuem sinalização para encorajar os visitantes a conhecerem a cidade em toda a sua extensão. Isto leva à aglomeração, lotação ou concentração de turistas nos locais com acesso mais fácil, os quais exercem grande atratividade, havendo, desta forma, uma grande dispersão em outras áreas da cidade ou no seu ambiente mais amplo. Em outras palavras, a oferta inadequada de transporte pode impedir a cidade de mostrar aos visitantes todos os seus atrativos, concentrando, desta forma, o turismo urbano em um número limitado de locais ao invés de propiciar uma gama mais ampla de recursos e mostrar todo o seu potencial turístico.

Conforme Ferraz e Torres(2004), os principais problemas provocados pelo uso massivo de automóveis, tantos nas regiões turísticas, quanto nas cidades, são principalmente:

- Congestionamentos que provocam baixa velocidade de circulação, com prejuízo inclusive para o transporte coletivo realizado junto com o trânsito geral;

- Poluição da atmosfera com substâncias tóxicas que pode tanto prejudicar a saúde das pessoas e animais, como também contaminar e deteriorar lugares e objetos históricos;

- Necessidade de grandes investimentos de recursos públicos na infra-estrutura viária em detrimento de outros setores de maior relevância social, como saúde e educação. 
- Ocorrência de um grande número de acidentes que podem causar perdas de vidas, de lesões graves e prejuízos financeiros.

De toda a carga movimentada no Brasil, 58\% é realizada pelo modo rodoviário. Uma boa parte destas circula pelos centros urbanos atendendo às demandas crescentes da população tanto em quantidade quanto em variedade de produtos para consumo. Isso tem provocado um grande número de problemas como restrições de tráfego e o aumento do risco sobre os demais veículos e sobre os pedestres; obstruções ao trânsito com conseqüiente redução da velocidade; congestionamentos, que por sua vez acarretam maior consumo de combustível, maiores tempos de viagem, incremento na poluição sonora, atmosférica e visual, vibrações, doenças, mortes e acidentes; perda de espaços verdes e espaços abertos reduzindo a qualidade de vida das pessoas e o aumentando o custo do serviço de transporte de carga, com o conseqüente aumento no custo final dos produtos.

Assim, considerando que a atividade de transporte é importante na cadeia produtiva em que está inserida e a sustentabilidade das indústrias de que dela dependem está diretamente relacionada às suas operações, empresas de transporte de pessoas e de cargas devem buscar diferenciar-se pelos serviços que oferecem tentando obter uma vantagem sustentável em relação à confiabilidade, disponibilidade e qualidade, bem como estabelecer estratégias econômicas, ambientais e sociais visando a sustentabilidade do negócio em longo prazo. Estratégias inapropriadas para este setor resultam em serviços que agravam as condições de pobreza, de saúde e prejudicam o meio ambiente. Sendo assim, merece destaque na formulação de estratégias para melhorar sua eficiência, sua aceitabilidade e sua sustentabilidade.

É importante a contribuição para que empresas de transporte de carga tenham planos que lhes permitam obter vantagens competitivas e retorno econômico incluindo benefício ambiental e social no pensamento estratégico oferecendo funcionalidades que sejam percebidas pelos clientes como valor agregado. Da mesma forma, novas contribuições devem ser feitas no sentido de propor novas estratégias para a gestão do transporte de cargas de modo que contemplem a utilização de recursos de forma eficiente e ambientalmente correta, contribuindo para o desenvolvimento econômico e cujos benefícios atinjam várias camadas da sociedade.

\section{CONCLUSÃO}

Estudos sobre sistemas de transportes e previsões de oferta e demanda por viagens podem ser elaborados sem levar em consideração o turismo. O inverso, entretanto, não pode acontecer: não existe sentido em se pensar em turismo sem se levar em conta os meios de transporte e a realização das viagens, ou seja: sem transporte entre o local de residência e o destino de interesse, o turismo será impossível. O transporte é uma parte integrante da indústria do turismo. Pode-se afirmar, com certeza, que a melhoria da eficiência dos sistemas de transportes, tarifas mais baixas, maior acessibilidade para áreas antes consideradas periféricas, é que tem permitido a grande expansão observada nos últimos anos do setor turístico.

O turismo é uma das atividades humanas que apresenta maiores taxas de crescimento, sua importância para a economia mundial é inegável, milhares de empregos são criados diariamente e o nível de desenvolvimento de diversas regiões do globo tem sido incrementado consideravelmente, o planejamento da logística para abastecê-lo e mantê-lo torna-se, portanto, tarefa crítica e que não pode ser negligenciada. 


\section{BIBLIOGRAFIA REFERENCIADA E CONSULTADA}

[1] Andrade, Jonas Pereira. (1994) Planejamento de transportes. Editora Universitária de UFPB, João Pessoa.

[2] Andrade, José V. (1998). Turismo: fundamentos e dimensões. Ática, 4. ed. São Paulo.

[3] ANTT - Agência Nacional de Transportes Terrestres - http://www.antt.gov.br/ - acessado em 05/08/2010

[4] Arantes, Débora Zanela (2009) Mapa estratégico dos cruzeiros marítimos: as transformações necessárias ao desenvolvimento do setor no Brasil. MonografiaUniversidade Federal do Rio Grande do Norte . Natal

[5] Banister, David. 2002. Transport Planning - Transport, Development and Susteainability, $2^{\mathrm{a}}$ ed. Taylor \& Francis.London.

[6] Bertaglia, Paulo Roberto (2003) - Logística e gerenciamento da cadeia de abastecimento. Saraiva, São Paulo.

[7] Cooper, Chris ett all (2007) Turismo, princípios e práticas. Bookmann, Porto Alegre.

[8] Ferraz, Antônio C. e Torres, Isaac G. (2004) Transporte público urbano- Rima, São Carlos.

[9] Gonçalves, Ilania (2009) Turismo-e-meio-ambiente-impactos-ambientais-e-sustentabilidade, http://www.webartigos.com/articles. acessado em outubro de 2010.

[10] Gossling, S. (2002). Global environmental consequences of tourism. Global Environmental Change, 12, 283-302.

[11] Gronau, W., \& Kagermeier, A. (2007). Key factors for successful leisure and tourism public transport provision. Journal of Transport Geography, 15, 127-135.

[12] Høyer, K. (2000). Sustainable tourism or sustainable mobility? The Norwegian case. Journal of $\quad$ Sustainable $\quad$ Tourism, $8(2)$, 147-159. http://www.agsolve.com.br/noticia.php?cod=744 Acessado em 01/11/2010

[13] Martín-Cejas, Roberto R. e SANCHEZ, Pedro P. R. (2010) Ecological footprint analysis of road transport related to tourism activity: The case for Lanzarote Island. Tourism Management 31 (2010) 98-103 Elsevier

[14] Mello, José Carlos. (1984) Transportes e desenvolvimento econômico. EBTU, Brasília.

[15] Ministério das Cidades (2004), Política Nacional de Mobilidade Urbana Sustentável. Brasilia

[16] Page, Stephen J. (2008) - Transportes e turismo- Perspectivas globais. Bookman, 2a . Ed. Porto Alegre.

[17] Palhares, Guilherme Lohmann. Transportes turísticos. Aleph,São Paulo: 2002.

[18] Santos, Lílian da Silva et all A avaliação do transporte rodoviário interestadual e internacional de passageiros enquanto serviço turístico. Disponível em http://www.etur.com.br/. Acessado em julho de 2010

[19] Sorupia, Eden (2005) Rethinking the role of transportation in tourism. Proceedings of the Eastern Asia Society for Transportation Studies, Vol. 5, p. 1767-1777, 2005 5, pp. 1767 1777,2005 